\title{
ANALISIS DINDING PENAHAN TANAH DI DAERAH ALIRAN SUNGAI MENGGUNAKAN PROGRAM MIDAS GTS NX
}

\author{
James Bastian Halim ${ }^{1}$ dan Chaidir Anwar Makarim² \\ ${ }^{1}$ Program Studi Sarjana Teknik Sipil, Universitas Tarumanagara, Jl. Letjen S. Parman No.1 Jakarta \\ james.325160086@stu.untar.ac.id \\ ${ }^{2}$ Program Studi Sarjana Teknik Sipil, Universitas Tarumanagara, Jl. Letjen S. Parman No.1 Jakarta \\ Chaidir259@gmail.com
}

Masuk: 30-06-2020, revisi: 25-07-2020, diterima untuk diterbitkan: 04-08-2020

\begin{abstract}
A retaining wall at a river bend in Depok cannot hold the soil behind the wall that cause the wall collapses and the soil landslide. The retaining wall is using shallow foundation. Therefore, a new wall is needed to prevent the land from sliding. The research method was using finite element method and Midas GTS NX program using 1 boring log data, $40 \mathrm{~cm} x 40 \mathrm{~cm}$ for pole size and three types of walls with different capping beam size. In this analysis, the value of L2 is smaller than L1, which indicated an unusual thing, in general the value of L2 is equal or greater than L1, L1 is length of the free pole and L2 is length of the pole through the ground surface. The value of $L 1$ can increase due to the river currents eroding riverbeds. The analysis showed the three types of walls has fulfilled the maximum limit of lateral deformation $8.4 \mathrm{~cm}$ and maximum limit moment from the brochure $224.2 \mathrm{kNm}$. From the three types of wall, type 1 wall is selected with displacement value of $2.454 \mathrm{~cm}$ and a maximum moment of $116.592 \mathrm{kNm}$. Type 1 wall were chosen because it require a minimum cost of Rp 458.821.479,072 less than others.
\end{abstract}

Keywords: retaining wall; pile; capping beam; river; finite element method

\begin{abstract}
ABSTRAK
Dinding penahan tanah disebuah tikungan sungai di Depok tidak dapat menahan tanah yang berada di belakangnya sehingga dinding tersebut roboh dan menyebabkan tanah di belakang dinding longsor. Dinding penahan tanah tersebut didesain dengan menggunakan pondasi dangkal. Oleh karena itu, diperlukan dinding penahan tanah yang baru dengan menggunakan tiang pancang untuk mencegah longsor lagi. Metode penelitian dilakukan dengan menggunakan metode elemen hingga dengan bantuan program Midas GTS NX dengan menggunakan 1 data boring log, ukuran tiang $40 \mathrm{~cm} \times 40 \mathrm{~cm}$ dan tiga tipe dinding dengan ukuran capping beam yang berbeda. Dalam analisis ini, besarnya nilai L2 lebih kecil dari L1 yang menunjukkan hal tidak lazim yang pada umumnya besarnya nilai L2 sama atau lebih besar dari L1 dimana L1 merupakan panjang tiang bebas dan L2 merupakan panjang tiang menembus permukaan tanah. Besarnya nilai L1 dapat meningkat akibat adanya arus sungai yang menggerus dasar sungai. Hasil analisis menunjukkan ketiga tipe dinding telah memenuhi syarat batas maksimum deformasi lateral dinding sebesar $8.4 \mathrm{~cm}$ dan batas maksimum momen dari brosur $224.2 \mathrm{kNm}$. Dari ketiga tipe dinding tersebut dipilih dinding tipe 1 dengan nilai displacement sebesar $2.454 \mathrm{~cm}$ dan momen maksimum $116.592 \mathrm{kNm}$. Dinding tipe 1 dipilih karena membutuhkan biaya paling minimum sebesar Rp 458.821.479,072 lebih kecil dibandingkan dengan tipe lainnya.
\end{abstract}

Kata kunci: dinding penahan tanah; tiang pancang; capping beam; sungai; metode elemen hingga

\section{PENDAHULUAN}

Dinding penahan tanah merupakan konstruksi yang dibuat untuk menahan tanah agar tidak terjadi longsor. Beberapa parameter yang perlu diperhatikan dalam analisis dinding penahan tanah antara lain tipe dinding, tekanan lateral tanah, berat jenis tanah, dan kondisi tanah. Selain itu, dalam menganalisis dinding penahan tanah perlu juga memperhatikan gaya guling, geser, serta daya dukung tanah dari dinding yang telah didesain tersebut.

Sebuah dinding penahan tanah yang berada di tikungan sungai di Depok terbuat dari pasangan batu gagal untuk menahan tanah dibelakangnya. Dinding tersebut sudah didesain sebanyak empat kali, namun masih terus mengalami kegagalan. Kegagalan yang terjadi diakibatkan oleh terjadinya hujan yang menyebabkan kenaikan air 
sungai yang mempengaruhi dinding penahan tersebut. Dinding penahan tanah yang sudah didesain sebelumnya menggunakan pondasi dangkal tidak dapat menahan tanah dan arus sungai sehingga dinding penahan tanah tersebut longsor. Oleh karena itu, diperlukan dinding penahan tanah yang baru yang dapat menahan tanah tersebut agar tidak longsor. Dinding penahan tanah yang baru didesain dengan menggunakan pondasi dalam berupa tiang pancang yang disusun memanjang dan diikat dengan capping beam.

Dalam menganalisis kekuatan dinding penahan tanah, salah satu metode yang dapat digunakan adalah metode elemen hingga. Kelebihan dari metode ini adalah dapat menunjukkan perilaku kekakuan dari dinding penahan tanah yang sudah didesain dan dapat menunjukkan titik-titik kritis yang rawan dari dinding penahan tanah tersebut.

Semakin berkembangnya teknologi, maka muncul beberapa software yang dapat mempermudah dalam menganalisis dinding penahan tanah. Salah satu software yang dapat digunakan adalah Midas GTS NX. Midas GTS $N X$ merupakan sebuah program komputer yang dapat mempermudah dalam menganalisis dinding penahan tanah menggunakan metode elemen hingga dan dapat memberikan hasil yang lebih optimal dan lebih akurat. Dalam program Midas GTS NX hasil output yang dihasilkan berupa displacement, stress dan moment.

Tujuan dilakukannya analisis dinding penahan tanah adalah untuk mengetahui apakah dinding penahan tanah dapat menahan tanah dan mencegak terjadinya longsor dengan membandingkan nilai displacement dan bending moment yang terjadi pada dinding.

\section{Dinding penahan tanah}

Dinding penahan tanah adalah sebuah struktur yang berfungsi untuk menahan timbunan tanah yang berada dibelakangnya untuk mencegah terjadinya longsor. Namun, material yang ditahan dapat memberi dorongan terhadap dinding penahan tanah yang menyebabkan dinding penahan tanah tersebut terguling dan tergeser (Dhamdhere, Rathi, \& Kolase, 2018)

\section{N-SPT}

Uji penetrasi standar (SPT) merupakan salah satu cara pengujian tanah yang dilakukan untuk memperoleh parameter fisik maupun kekuatan tanah. Dalam uji SPT akan diperoleh sampel tanah perlapisan tanah dan nilai NSPT. Nilai N-SPT menunjukkan jumlah pukulan yang diperlukan untuk mencapai kedalaman tertentu. Nilai NSPT dapat digunakan untuk menentukan kohesi tanah (c), sudut geser dalam $(\varnothing)$, relative density (Dr), undrained shear strength $(\mathrm{Su})$ dan gelombang geser tanah $(\mathrm{Vs})$.

\section{Modulus young (Es)}

Modulus young merupakan perbandingan antara tegangan dan regangan yang menunjukkan kemampuan suatu material untuk kembali ke bentuk semula apabila diberi suatu gaya dan menggambarkan kekakuan suatu material. Apabila nilai modulus young semakin besar maka, perubahan bentuk akibat tegangan semakin kecil. Nilai modulus elastisitas dapat dilihat pada Tabel.1.

Tabel 1. Hubungan jenis tanah dan modulus elastisitas

\begin{tabular}{cc}
\hline Jenis Tanah & Es $\left(\mathrm{kN} / \mathrm{m}^{2}\right)$ \\
\hline Sand (Normally Consolidated) & $500(\mathrm{~N}+15)$ \\
& $7000 \mathrm{~N} 0,5$ \\
Sand (Saturated) & $6000 \mathrm{~N}$ \\
Sand, all (Normally Consolidated) & $(15000-22000) \ln \mathrm{N}$ \\
Sand (overconsolidated) & $250(\mathrm{~N}+15)$ \\
Gravelly Sand & $4000+1050 \mathrm{~N}$ \\
Clayey Sand & $1200(\mathrm{~N}+6)$ \\
Silt, Sandy Silt or Clayey Silt & $600(\mathrm{~N}+6), \mathrm{N}<15$ \\
(Sumber: Bowles, 1997)
\end{tabular}




\section{Poisson ratio (v)}

Poisson ratio merupakan rasio perbandingan antara regangan horisontal dengan regangan vertikal. Nilai poisson ratio ditentukan sebagai rasio kompresi poros terhadap regangan pemuaian lateral (Sabina, 2020). Nilai poisson ratio dapat dilihat pada Tabel.2.

Tabel 2. Hubungan jenis tanah dan poisson ratio

\begin{tabular}{cc}
\hline Type of Soil & Poisson's Ratio (v) \\
\hline Clay, saturated & $0,4-0,5$ \\
Clay, unsaturated & $0,1-0,3$ \\
Sand clay & $0,2-0,3$ \\
Silt & $0,3-0,35$ \\
Sand, gravelly sand & $0,1-1$ \\
Commonly used & $0,3-0,4$ \\
Rock (depends somewhat on & \\
type of rock) & $0,1-0,4$ \\
Loess & $0,1-0,3$ \\
Ice & 0,36 \\
Steel & 0,15 \\
(Sumber: Bowles,1997)
\end{tabular}

\section{Berat jenis $(\gamma)$}

Berat jenis merupakan perbandingan antar massa suatu benda dengan volume atau kerapatan suatu partikel secara keseluruhan. Berat jenis saturasi adalah berat tanah ketika pori-pori yang kosong pada suatu tanah terisi oleh air sepenuhnya dan tidak ada udara. Nilai berat jenis dapat dilihat pada Tabel.3.

Tabel 3. Hubungan antara jenis tanah dan berat jenis

\begin{tabular}{ccc}
\hline Soil & $\boldsymbol{\gamma}_{\text {sat }}\left(\mathrm{kN} / \mathrm{m}^{3}\right)$ & $\boldsymbol{\gamma}\left(\mathrm{kN} / \mathrm{m}^{3}\right)$ \\
\hline Gravel & $20-22$ & $15-17$ \\
Sand & $18-20$ & $13-16$ \\
Silt & $18-20$ & $14-18$ \\
Clay & $16-22$ & $14-21$
\end{tabular}

(Sumber: John Wiley \& Sons, 2000)

\section{Sudut geser dalam $(\varnothing)$}

Sudut geser dalam merupakan sudut yang terbentuk jika suatu material diberi tegangan atau gaya yang melebihi tegangan gesernya atau terbentuk akibat dari tegangan normal dengan tegangan geser suatu material. Nilai sudut geser dalam diperoleh dari kekasaran antara butiran tanah dan pada umumnya nila sudut geser dalam yang besar ditemukan pada tanah berbutir. Nilai sudut geser dalam dapat dilihat pada Tabel.4.

Tabel 4. Hubungan antara jenis tanah dan sudut geser dalam

\begin{tabular}{ccc}
\hline Soil & Density / Consistency & $\emptyset\left(^{\circ}\right)$ \\
\hline Sands & Very Loose & $<30$ \\
& Loose & $30-35$ \\
& Medium Dense & $35-38$ \\
& Dense & $38-41$ \\
& Very Dense & $41-44$ \\
\hline
\end{tabular}

(Sumber : Ankita, 2019) 
Lanjutan Tabel 4. Hubungan antara jenis tanah dan sudut geser dalam

\begin{tabular}{ccc}
\hline Soil & Density / Consistency & $\emptyset\left(^{\circ}\right)$ \\
\hline Cohesive Soils & Very Soft & N/A \\
& Firm & N/A \\
& Stiff & N/A \\
& Very Stiff & N/A \\
& Hard & N/A \\
\hline
\end{tabular}

(Sumber: Ankita, 2019)

\section{Kohesi (c)}

Kohesi merupakan gaya tarik menarik antara partikel yang sejenis. Nilai kohesi muncul akibat adanya lekatan antara nilai N-SPT dengan butiran tanah. Nilai kohesi dapat dilihat pada Tabel.5.

Tabel 5. Hubungan antara jenis tanah dan kohesi

\begin{tabular}{cc}
\hline N-SPT & Kohesi $(\mathrm{c})\left(\mathrm{kN} / \mathrm{m}^{2}\right)$ \\
\hline$<2$ & 12,5 \\
$2-4$ & $12,5-25$ \\
$4-8$ & $25-50$ \\
$8-15$ & $50-100$ \\
$15-30$ & $100-200$ \\
$>30$ & $>200$ \\
\hline
\end{tabular}

(Sumber: Ameratunga, Sivakugan, \& Das, 2015)

\section{Koefisien tekanan lateral diam}

Koefisien tekanan lateral diam merupakan keadaan dimana dinding tidak bergerak dan tanah berada dalam keseimbangan elastis (elastic equilibrium) (Leonsius, 2012). Nilai koefisien tekanan lateral diam dapat dilihat pada Tabel.6.

Tabel 6. Hubungan antara jenis tanah dan koefisien tekanan lateral diam

\begin{tabular}{ccccc}
\hline Soil & OCR $=1$ & OCR $=2$ & OCR $=5$ & OCR $=10$ \\
\hline Loose Sand & 0,50 & 0,65 & 1,10 & 1,50 \\
Medium Dense Sand & 0,40 & 0,60 & 1,05 & 1,55 \\
Dense Sand & 0,35 & 0,55 & 1,00 & 1,50 \\
Silt & 0,50 & 0,70 & 1,10 & 1,60 \\
Lean Clay, CL & 0,60 & 0,80 & 1,20 & 1,65 \\
High Plasticity Clay, CH & 0,65 & 0,80 & 1,10 & 1,40 \\
\hline
\end{tabular}

(Sumber: Gouw, 2009)

\section{Metode elemen hingga}

Metode elemen hingga (Finite Element Method) merupakan salah satu metode numerik yang membuat persamaan matematis dengan berbagai pendekatan dan rangkaian persamaan aljabar yang melibatkan nilai-nilai pada titiktitik diskrit pada bagian yang dievaluasi. Pada metode elemen hingga, daerah yang dianalisis dibagi menjadi beberapa elemen (Hamdhan \& Pratiwi, 2017)

\section{METODE PENELITIAN}

Dalam penelitian yang dilakukan ini, terdapat beberapa tahapan yaitu:

- $\quad$ Tahap pertama, menentukan data perencanaan yang akan digunakan untuk analisis.

- $\quad$ Tahap kedua, mengumpulkan teori-teori yang digunakan untuk melakukan analisis dinding penahan tanah menggunakan tiang pancang dengan metode elemen hingga berupa buku-buku, jurnal dan tutorial. 
- $\quad$ Tahap ketiga, mengkorelasikan data-data tanah yang sudah didapat dan menentukan parameter-parameter yang dibutuhkan untuk analisis.

- $\quad$ Tahap keempat, melakukan input pada program dari data-data tanah yang sudah dikorelasikan dan melakukan analisis dinding penahan tanah.

- $\quad$ Tahap kelima, membandingkan hasil output berupa displacement yang didapat dari SNI 8460-2017 dan bending moment yang didapat dari brosur.

- $\quad$ Tahap keenam, pemilihan tipe dinding dengan membandingkan harga yang dibutuhkan oleh setiap desain dinding penahan tanah.

\section{HASIL DAN PEMBAHASAN}

Analisis dilakukan dengan menggunakan metode elemen hingga dengan bantuan program Midas GTS NX dengan menggunakan 1 data borlog. Tabel 7 menggambarkan parameter tanah yang digunakan untuk diinput dalam program Midas GTS NX:

Tabel 7. Parameter tanah

\begin{tabular}{|c|c|c|c|c|c|c|c|c|c|c|}
\hline $\begin{array}{l}\text { Kedalaman } \\
\text { (m) }\end{array}$ & $\begin{array}{l}\text { Jenis } \\
\text { Tanah }\end{array}$ & $\begin{array}{l}\mathrm{N}- \\
\text { SPT }\end{array}$ & $\begin{array}{l}\text { N-SPT } \\
\text { Koreksi }\end{array}$ & Es $\left(\mathrm{kN} / \mathrm{m}^{2}\right)$ & $\mathrm{v}$ & $\begin{array}{c}\boldsymbol{\gamma} \\
\left(\mathrm{kN} / \mathrm{m}^{3}\right)\end{array}$ & $\begin{array}{c}\boldsymbol{\gamma}_{\boldsymbol{s a t}} \\
\left(\mathrm{kN} / \mathrm{m}^{3}\right)\end{array}$ & $\begin{array}{c}\emptyset \\
\left(^{\circ}\right)\end{array}$ & $\begin{array}{c}\mathrm{c} \\
\left(\mathrm{kN} / \mathrm{m}^{2}\right)\end{array}$ & $\mathrm{K}_{0}$ \\
\hline $0-6$ & Silt & 5 & 5 & 3300 & 0,35 & 18 & 20 & - & 31,25 & 0,5 \\
\hline $6-8$ & Silt & 12 & 12 & 5400 & 0,35 & 18 & 20 & - & 78,57 & 0,5 \\
\hline $8-12$ & Clay & 38 & 26 & 9600 & 0,45 & 21 & 22 & - & 146,667 & 0,65 \\
\hline $12-16$ & Sand & 50 & 32 & 11750 & 0,1 & 16 & 20 & 41 & - & 0,35 \\
\hline $16-20$ & Silt & 50 & 32 & 11400 & 0,35 & 18 & 20 & - & 250 & 0,5 \\
\hline Beton K-500 & - & - & - & 30277632,0078 & 0,2 & 24 & 24 & - & - & - \\
\hline
\end{tabular}

\section{Tipe dinding}

Dalam analisis ini, ada tiga tipe diding yang digunakan. Tabel 8 menjelaskan tipe dinding dan jarak antar tiang yang digunakan:

Tabel 8. Tipe dinding

\begin{tabular}{ccc}
\hline Tipe Dinding & Ukuran Capping Beam & Jarak Antar Tiang \\
\hline Tipe 1 & $80 \mathrm{~cm} \mathrm{x} 40 \mathrm{~cm}$ & $80 \mathrm{~cm}$ \\
Tipe 2 & $60 \mathrm{~cm} \mathrm{x} 40 \mathrm{~cm}$ & $60 \mathrm{~cm}$ \\
Tipe 3 & $60 \mathrm{~cm} \mathrm{x} \mathrm{40} \mathrm{cm}$ & $40 \mathrm{~cm}$ \\
\hline
\end{tabular}

\section{Deformasi lateral}

Batasan deformasi lateral izin dinding penahan tanah mengikuti SNI 8460:2017 yang ditentukan oleh kondisi tanah, kedalaman galian serta jarak dan kondisi gedung terdekat yang besarnya ditentukan oleh tabel dibawah ini.

Tabel 9. Batas maksimum deformasi lateral dinding (SNI 8460:2017)

\begin{tabular}{|c|c|c|c|c|}
\hline $\begin{array}{l}\text { Batas Maksimum Deformasi Lateral } \\
\text { pada Dinding }\end{array}$ & \multicolumn{4}{|c|}{ Lokasi Gedung dan Infrastruktur Eksisting Terdekat } \\
\hline Batas Maksimum Deformasi Lateral & \multicolumn{4}{|c|}{ Zona $3(\mathrm{x} / \mathrm{H}>2)$} \\
\hline $\begin{array}{l}\text { Keterangan: } \\
\mathrm{x}=\text { jarak dari batas galian, } \\
\mathrm{H}=\text { kedalaman galian, } \\
\qquad \delta \mathrm{W}=\text { defleksi dinding }\end{array}$ & $\begin{array}{c}\text { Zona } 1 \\
(\mathrm{x} / \mathrm{H}<1)\end{array}$ & $\begin{array}{c}\text { Zona } 2 \\
(1 \leq \mathrm{x} / \mathrm{H} \leq 2)\end{array}$ & $\begin{array}{l}\text { Tanah } \\
\text { Tipe A }\end{array}$ & $\begin{array}{l}\text { Tanah } \\
\text { Tipe B }\end{array}$ \\
\hline $\begin{array}{l}\text { Batas izin maksimum deformasi } \\
(\delta \mathrm{w} / \mathrm{H})\end{array}$ & $0,5 \%$ & $0,7 \%$ & $0,7 \%$ & $1,0 \%$ \\
\hline
\end{tabular}


a) Tanah Tipe A meliputi: tanah lempung dan lanau overconsolidated (over-consolidated stiff clays dan silts), tanah residual (residual soils), dan tanah pasir dengan kepadatan sedang sampai dengan padat (medium to dense sands).

b) Tipe Tanah B meliputi: tanah lempung dan lanau lunak (soft clays, silts), tanah organik (organic soils) dan tanah timbunan tidak terpadatkan (loose fills).

Dengan demikian, batas maksimum deforasi lateral dinding adalah sebesar $8.4 \mathrm{~cm}$. Variabel x menjukkan jarak ke gedung terdekat sedangkan dilokasi tidak terdapat gedung disekitarnya sehingga didapat nilai x/H > 2 .

\section{Momen maksimum}

Batasan momen maksimum yang dapat dipikul oleh tiang dilihat berdasarkan brosur tiang yang diproduksi oleh salah satu produsen tiang. Brosur yang digunakan merupakan tiang yang diproduksi oleh PT Wijaya Karya Beton Tbk. Dengan demikian, digunakan tiang dengan ukuran $40 \mathrm{~cm}$ x $40 \mathrm{~cm}$ tipe D dengan batas momen maksimum sebesar $224.2 \mathrm{kNm}$. Brosur tiang beton K-500 dapat dilihat pada Gambar.1.

\begin{tabular}{|c|c|c|c|c|c|c|c|c|c|c|c|}
\hline \multicolumn{8}{|c|}{$\begin{array}{l}\text { PRESTRESSED CONCRETE SQUARE PILES SPECIFICATION } \\
\text { Concrete Compressive Strength } \mathrm{fc}^{\prime}=42 \mathrm{MPa}\left(\text { Cube } 500 \mathrm{~kg} / \mathrm{cm}^{2}\right)\end{array}$} & \multicolumn{4}{|c|}{ Unit Conversion : 1 ton $=9.8060 \mathrm{kN}$} \\
\hline \multirow{2}{*}{$\begin{array}{l}\text { Size } \\
(\mathrm{mm})\end{array}$} & \multirow{2}{*}{$\begin{array}{l}\text { Cross } \\
\text { Section } \\
\left(\mathrm{cm}^{2}\right)\end{array}$} & \multirow{2}{*}{$\begin{array}{l}\text { Section } \\
\text { Inertia } \\
\left(\mathrm{cm}^{4}\right)\end{array}$} & \multirow{2}{*}{$\begin{array}{c}\text { Unit } \\
\text { Weight } \\
(\mathrm{kg} / \mathrm{m})\end{array}$} & \multirow[b]{2}{*}{ Class } & \multicolumn{2}{|c|}{ Bending Moment } & \multirow{2}{*}{$\begin{array}{l}\text { Allowable } \\
\text { Compression } \\
\text { (ton) }\end{array}$} & \multirow{2}{*}{$\begin{array}{l}\text { Decompression } \\
\text { Tension } \\
\text { (ton) }\end{array}$} & \multirow{2}{*}{$\begin{array}{l}\text { Length } \\
\text { of Pile* } \\
(\mathrm{m})\end{array}$} & \multicolumn{2}{|c|}{ Splice Class } \\
\hline & & & & & $\begin{array}{l}\text { Crack } \\
\text { (ton.m) }\end{array}$ & $\begin{array}{l}\text { Ultimate } \\
\text { (ton.m) }\end{array}$ & & & & $\begin{array}{l}\text { Compatible } \\
\text { to Body Marak }\end{array}$ & Optional \\
\hline $200 \times 200$ & 400 & 13,333 & 100 & A & 1.55 & 2.65 & 49.08 & 27.47 & 6.9 & 1 & II \\
\hline \multirow[t]{3}{*}{$250 \times 250$} & 625 & 32,552 & 156 & A & 2.29 & 3.46 & 81.40 & 28.10 & $6-10$ & IIII & IV \\
\hline & & & & B & 2.52 & 4.33 & 79.62 & 34.80 & $6-11$ & ॥ & - \\
\hline & & & & C & 2.78 & 5.19 & 77.92 & 41.30 & $6-11$ & 1 & II \\
\hline \multirow{4}{*}{$300 \times 300$} & 900 & 67,500 & 225 & A & 3.64 & 5.19 & 118.59 & 35.40 & $6-11$ & N & v \\
\hline & & & & B & 3.98 & 6.23 & 116.76 & 42.20 & $6-11$ & III & IV $N$ \\
\hline & & & & c & 4.48 & 7.47 & 114.66 & 50.20 & $6-12$ & ॥ & - \\
\hline & & & & D & 4.92 & 9.34 & 111.60 & 61.90 & $6=12$ & 1 & III/IV/N \\
\hline \multirow[t]{4}{*}{$350 \times 350$} & 1,225 & 125,052 & 306 & A & 5.33 & 6.57 & 163.98 & 38.60 & $6-11$ & IIII & IV \\
\hline & & & & B & 6.07 & 8.72 & 160.68 & 50.90 & $6-12$ & ॥ & - \\
\hline & & & & c & 6.63 & 10.90 & 157.45 & 63.10 & $6-12$ & 1 & IV \\
\hline & & & & D & 7.30 & 13.08 & 154.32 & 75.00 & $6-13$ & 1 & III/IV \\
\hline \multirow[t]{4}{*}{$400 \times 400$} & 1,600 & 213,333 & 400 & A & 7.89 & 9.96 & 213.96 & 51.40 & $6-12$ & N & V \\
\hline & & & & B & 8.71 & 12.45 & 210.60 & 63.80 & $6-12$ & III & IV $/ \mathrm{N}$ \\
\hline & & & & c & 9.51 & 14.95 & 207.32 & 76.00 & $6-13$ & ॥I & III/IV/N \\
\hline & & & & D & 11.82 & 22.42 & 198.01 & 111.60 & $6-14$ & 1 & II/III/IV/N \\
\hline \multirow[t]{4}{*}{$450 \times 450$} & 2,025 & 341,719 & 506 & A & 11.17 & 14.01 & 270.98 & 64.30 & $6-12$ & III & IV \\
\hline & & & & B & 12.10 & 16.81 & 267.61 & 76.80 & $6-13$ & IIII & IV \\
\hline & & & & c & 13.01 & 19.62 & 264.30 & 89.10 & $6-13$ & ॥ & III/IV \\
\hline & & & & D & 14.78 & 25.22 & 257.88 & 113.30 & $6-14$ & 1 & II/IIIIV \\
\hline \multirow[t]{4}{*}{$500 \times 500$} & 2,500 & 520,833 & 625 & A & 15.16 & 18.68 & 335.12 & 77.30 & $6 \cdot 13$ & III & IV \\
\hline & & & & B & 16.19 & 21.79 & 331.72 & 89.90 & $6-13$ & ॥ & IIII/V \\
\hline & & & & C & 17.21 & 24.91 & 328.38 & 102.20 & $6-14$ & I & IIIIIIIIV \\
\hline & & & & D & 18.22 & 28.02 & 325.09 & 114.50 & $6-14$ & 1 & IIIIII/IV \\
\hline
\end{tabular}

Gambar 1. Brosur tiang K-500 (Sumber: PT Wijaya Karya Beton, 2017)

\section{Hasil analisis}

Setelah melakukan analisis dengan program Midas GTS NX, didapat besarnya displacement dan bending moment dari program Midas GTS NX. Berikut tabel rangkuman dari hasil analisis:

Tabel 10. Hasil analisis

\begin{tabular}{ccc}
\hline Tipe Dinding & Displacement & Bending Moment \\
\hline Tipe 1 & $2,454 \mathrm{~cm}$ & $116,592 \mathrm{kNm}$ \\
Tipe 2 & $2,459 \mathrm{~cm}$ & $112,861 \mathrm{kNm}$ \\
Tipe 3 & $2,459 \mathrm{~cm}$ & $112,859 \mathrm{kNm}$ \\
\hline
\end{tabular}

\section{Analisis harga}

Setelah mendapatkan besarnya nilai displacement dan momen maksimum dari setiap desain yang digunakan, ketiga desain tersebut memenuhi syarat deformasi lateral dan momen maksimum yang sudah ditentukan. Oleh karena itu, perlu dianalisis harga untuk mengetahui biaya minimum dari setiap desain. Harga yang dianalisis hanya harga material tanpa memperhitungkan biaya pekerja dan alat yang digunakan. Harga tiang yang digunakan merupakan tiang yang diproduksi oleh PT Gemilan Beton Precast. Daftar harga square pile dapat dilihat pada Tabel.11 dan analisis harga beton K-500 dapat dilihat pada Tabel.12 
Tabel 11. Daftar harga square pile (Tiang 6 meter)

\begin{tabular}{|c|c|}
\hline Spesifikasi & Terkirim/meter (Rp/meter)(tiang 6 meter) \\
\hline SQ $20 \times 6 \mathrm{~S}(4 \times d 10 \mathrm{~mm})$ & $110.911,00$ \\
\hline SQ $20 \times 6 \mathrm{D}(4 \times \mathrm{d} 10 \mathrm{~mm})$ & $115.238,00$ \\
\hline SQ $20 \times 6 \mathrm{~S}(4 \times d 13 \mathrm{~mm})$ & $129.986,00$ \\
\hline SQ $20 \times 6 \mathrm{D}(4 \times \mathrm{d} 13 \mathrm{~mm})$ & $134.313,00$ \\
\hline SQ 25 x $6 \mathrm{~S}(4 \mathrm{xd} 13 \mathrm{~mm})$ & $170.396,00$ \\
\hline SQ $25 \times 6 \mathrm{D}(4 \times \mathrm{dd} 13 \mathrm{~mm})$ & $177.451,00$ \\
\hline SQ $25 \times 6 \mathrm{~S}(4 \times d 16 \mathrm{~mm})$ & $194.922,00$ \\
\hline SQ $25 \times 6 \mathrm{D}(4 \times \mathrm{d} 16 \mathrm{~mm})$ & $201.977,00$ \\
\hline SQ $30 \times 6 \mathrm{~S}(6 \times \mathrm{d} 13 \mathrm{~mm})$ & $257.668,00$ \\
\hline SQ $30 \times 6 \mathrm{D}(6 \times \mathrm{d} 13 \mathrm{~mm})$ & $267.262,00$ \\
\hline SQ $30 \times 6 \mathrm{~S}(4 \times d 16 \mathrm{~mm})$ & $258.576,00$ \\
\hline SQ $30 \times 6 \mathrm{D}(4 \times \mathrm{d} 16 \mathrm{~mm})$ & $268.534,00$ \\
\hline SQ $35 \times 6 \mathrm{~S}(8 \times d 13 \mathrm{~mm})$ & $343.019,00$ \\
\hline SQ $35 \times 6 \mathrm{D}(8 \times \mathrm{dd} 13 \mathrm{~mm})$ & $356.045,00$ \\
\hline SQ $35 \times 6 \mathrm{~S}(6 \times \mathrm{d} 16 \mathrm{~mm})$ & $356.191,00$ \\
\hline SQ $35 \times 6 \mathrm{D}(6 \times \mathrm{d} 16 \mathrm{~mm})$ & $369.216,00$ \\
\hline SQ $40 \times 6 \mathrm{~S}(8 \times d 13 \mathrm{~mm})$ & $416.864,00$ \\
\hline SQ $40 \times 6 \mathrm{D}(8 \times \mathrm{dd} 13 \mathrm{~mm})$ & $432.468,00$ \\
\hline $\mathrm{SQ} 40 \times 6 \mathrm{~S}(6 \times \mathrm{d} 16 \mathrm{~mm})$ & $430.036,00$ \\
\hline $\mathrm{SQ} 40 \times 6 \mathrm{D}(6 \times \mathrm{d} 16 \mathrm{~mm})$ & $445.639,00$ \\
\hline
\end{tabular}

(Sumber:PT Gemilan Beton Precast, 2016)

Tabel 12. Analisis harga satuan beton K-500

\begin{tabular}{|c|c|c|c|c|c|}
\hline No & Komponen & Satuan & Perkiraan Kuantitas & Harga Satuan (Rp) & Jumlah Harga (Rp) \\
\hline \multirow[t]{5}{*}{$\mathrm{A}$} & TENAGA & & & & \\
\hline & Pekerja (L01) & Jam & 5.3012 & - & - \\
\hline & Tukang (L02) & Jam & 1.7671 & - & - \\
\hline & Mandor (L03) & Jam & 0.4418 & - & - \\
\hline & \multicolumn{4}{|c|}{ JUMLAH TENAGA KERJA } & - \\
\hline \multirow[t]{7}{*}{$\mathrm{B}$} & BAHAN & & & & \\
\hline & Semen (M12) & $\mathrm{Kg}$ & 466.8522 & - & - \\
\hline & Pasir (M01) & $\mathrm{m} 3$ & 0.3631 & - & - \\
\hline & Agregat Kasar (M03) & $\mathrm{m} 3$ & 0.6588 & - & - \\
\hline & Kayu Perancah (M19) & $\mathrm{m} 3$ & 0.15 & - & - \\
\hline & Paku (M18) & $\mathrm{Kg}$ & 1.5 & - & - \\
\hline & \multicolumn{4}{|c|}{ JUMLAH HARGA BAHAN } & - \\
\hline \multirow[t]{7}{*}{$\mathrm{C}$} & PERALATAN & & & & \\
\hline & Conc. Mixer (E06) & Jam & 0.4418 & - & - \\
\hline & Water Tanker (E23) & Jam & 0.0527 & - & - \\
\hline & Con. Vibrator (E20) & Jam & 0.4418 & - & - \\
\hline & Con. Pump (E28) & Jam & 0.4418 & - & - \\
\hline & Alat Bantu & Ls & 1 & - & - \\
\hline & & & JUN & AH HARGA ALAT & - \\
\hline $\mathrm{D}$ & \multicolumn{4}{|c|}{ Jumlah Harga Tenaga, Bahan dan Peralatan $(A+B+C)$} & - \\
\hline $\mathrm{E}$ & Overhead \& Profit & & $10 \% \times \mathrm{D}$ & & - \\
\hline $\mathrm{F}$ & \multicolumn{4}{|c|}{ Harga Satuan Pekerjaan (D+E) } & - \\
\hline
\end{tabular}


Analisis harga satuan bahan beton K-500 dapat dilihat pada Tabel.13 dan rangkuman biaya dinding penahan tanah dapat dilihat pada Tabel.14.

Tabel 13. Analisis harga satuan bahan beton K-500

\begin{tabular}{|c|c|c|c|c|c|}
\hline No & Komponen & Satuan & $\begin{array}{l}\text { Perkiraan } \\
\text { Kuantitas }\end{array}$ & Harga Satuan (Rp) & Jumlah Harga $(\mathrm{Rp})$ \\
\hline \multirow[t]{7}{*}{ B } & BAHAN & & & & \\
\hline & Semen (M12) & $\mathrm{Kg}$ & 466.8522 & Rp 1.300,00 & Rp 606.907,86 \\
\hline & Pasir (M01) & $\mathrm{m} 3$ & 0.3631 & Rp 300.000,00 & Rp 108.930,00 \\
\hline & Agregat Kasar (M03) & $\mathrm{m} 3$ & 0.6588 & Rp 360.400,00 & Rp 237.431,52 \\
\hline & Kayu Perancah (M19) & $\mathrm{m} 3$ & 0.15 & Rp 3.250.000,00 & $\mathrm{Rp} \quad 487.500$ \\
\hline & Paku (M18) & $\mathrm{Kg}$ & 1.5 & Rp 17.000 & $\operatorname{Rp} 25.500,00$ \\
\hline & & & \multicolumn{2}{|c|}{ JUMLAH HARGA BAHAN } & Rp 1.466.269,38 \\
\hline
\end{tabular}

Tabel 14. Rangkuman biaya dinding penahan tanah

\begin{tabular}{cc}
\hline Tipe Dinding & \multicolumn{2}{c}{ Harga } \\
\hline Tipe 1 & Rp 458.821.479,072 \\
Tipe 2 & Rp 595.339.755,04 \\
Tipe 3 & Rp 882.452.493,024 \\
\hline
\end{tabular}

\section{Pemilihan tipe dinding}

Setelah melakukan analisis, ada hal yang jarang terjadi yaitu nilai L2 lebih kecil daripada L1 namun hal tersebut masih dapat dipertanggungjawabkan karena pada kondisi tanah tertentu nilai L2 dapat lebih kecil daripada nilai L1. Pada umumnya nilai L2 sama atau lebih besar dari L1. L1 merupakan panjang tiang bebas sepanjang $8.4 \mathrm{~m}$ dan L2 merupakan panjang tiang yang menembus permukaan tanah sepanjang $5.6 \mathrm{~m}$. Nilai L1 dan L2 dihitung dari ujung tiang dimana ujung tiang berada $2.3 \mathrm{~m}$ dibawah permukaan tanah. Besarnya nilai L1 dapat meningkat akibat adanya arus dari sungai yang menggerus dasar sungai. Untuk mengurangi dampak gerusan tersebut, dapat dipasang batu-batu untuk pemecah gelombang di sisi terbuka tiang.

Selain itu, melihat data tanah yang memilki kenaikan nilai N-SPT yang cukup drastis dari kedalaman 8 meter, ada kemungkinan tiang akan sulit untuk dipancang. Oleh karena itu, dapat dilakukan preboring terlebih dahulu sebelum dipancang. Untuk penggunaan ukuran mata bor dapat disesuaikan dengan ukuran tiang pancang yang idealnya ukuran mata bor lebih kecil dari ukuran tiang pancang supaya didapatkan friksi tiang pancang yang maksimal.

Hasil output menunjukkan tiga tipe dinding yang digunakan dengan ukuran tiang $40 \mathrm{~cm} \mathrm{x} 40 \mathrm{~cm}$ telah memenuhi syarat batas maksimum deformasi lateral dan batas momen maksimum dari brosur tiang, sehingga perlu dilakukan analisis harga untuk menentukan tipe dinding yang membutuhkan biaya paling minimum. Setelah dilakukan analisis harga, dinding tipe 1 membutuhkan biaya paling minimum sebesar Rp 458.821.479,072. Displacement maksimum yang terjadi pada dinding tipe 1 sebesar $2.454 \mathrm{~cm}$ dan momen maksimum yang terjadi sebesar 116.592 $\mathrm{kNm}$.

Dinding tipe 1 yang jarak antar tiangnya $80 \mathrm{~cm}$ akan menyisakan spacing yang dapat membuat tanah longsor ke sungai sehingga dibutuhkan pelat beton untuk menjaga tanah tersebut. Selain itu, pelat beton juga dapat memastikan beban tanah terbagi rata ke setiap tiang. Namun, karena pada analisis ini dinding dimodelkan dengan model 2 dimensi, pelat beton tidak dapat dimodelkan namun sudah teranalisis dalam program Midas GTS NX. Gambar.2 menunjukkan besarnya nilai displacement dari dinding tipe 1. Gambar.3 menunjukkan besarnya nilai bending moment dari dinding tipe 1. 


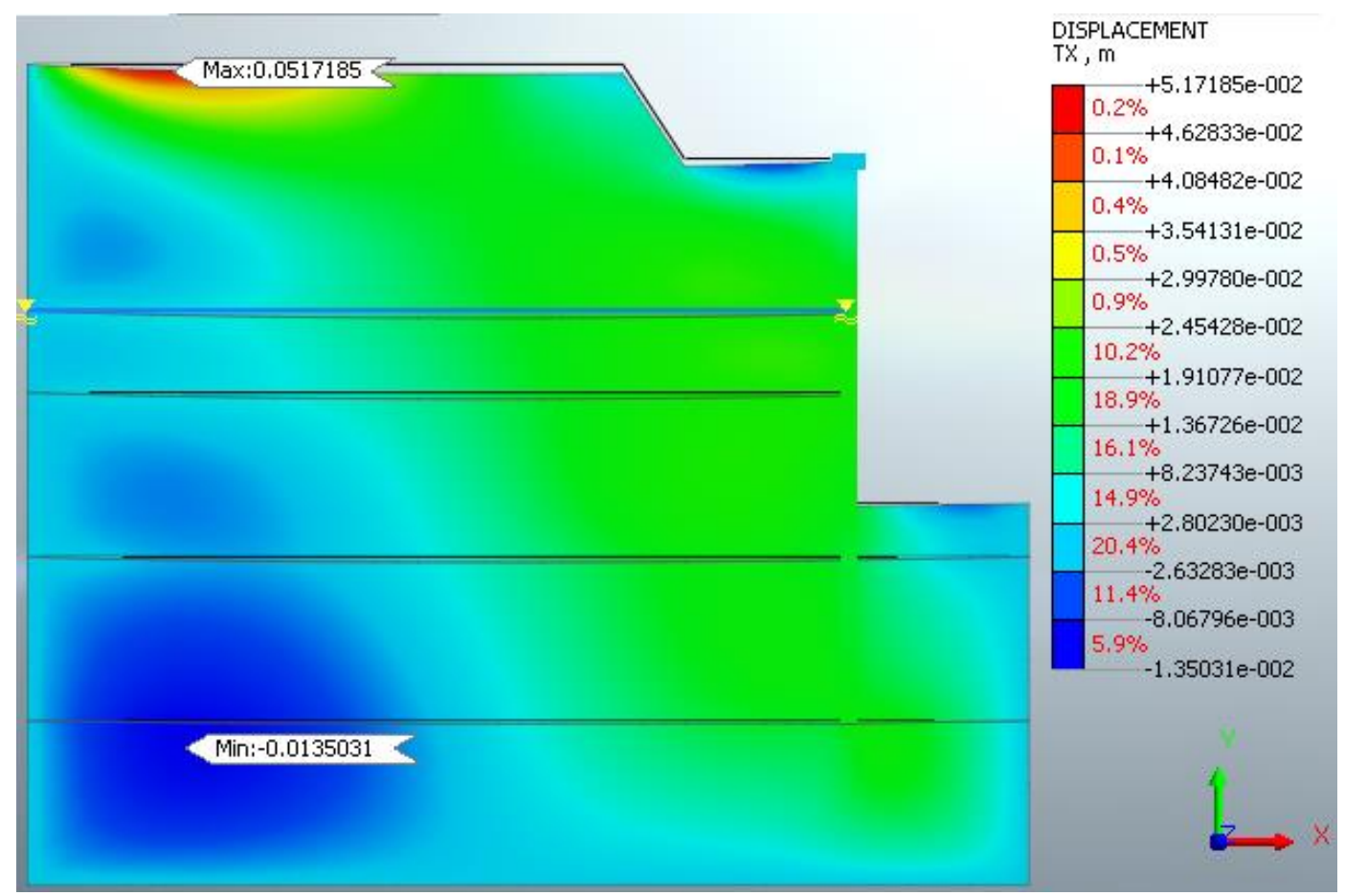

Gambar 2. Displacement dinding tipe 1

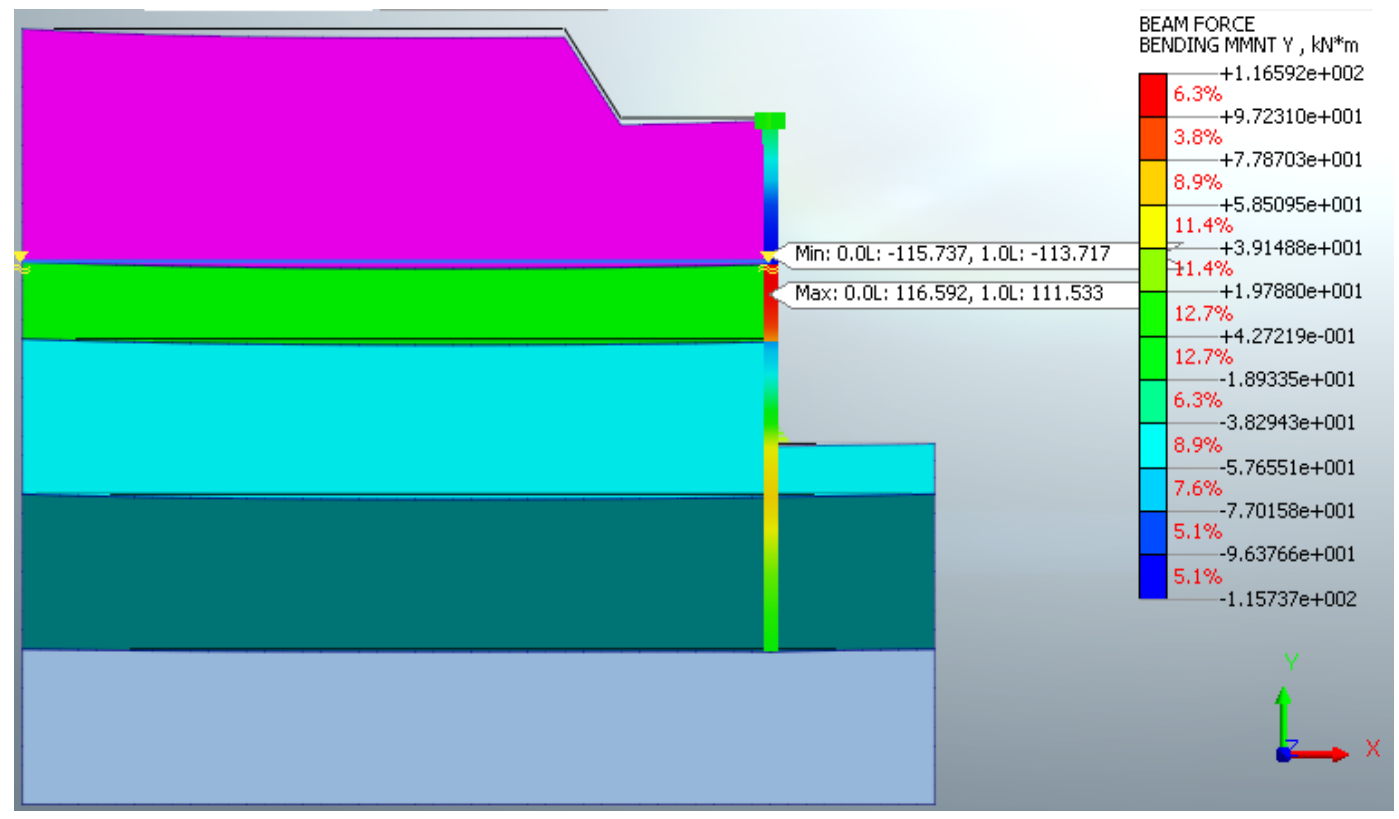

Gambar 3. Bending moment dinding tipe 1

\section{KESIMPULAN DAN SARAN}

\section{Kesimpulan}

Dari hasil analisis yang telah dilakukan, didapatkan beberapa hal yang dapat disimpulkan yaitu:

1. Desain yang telah dianalisis sudah memenuhi syarat deformasi lateral dari SNI 8460:2017 dan juga batas momen maksimum dari brosur spesifikasi tiang yang diproduksi oleh PT Wijaya Karya Beton Tbk. Desain yang dimaksud adalah desain Tipe 1, Tipe 2 dan Tipe 3. Desain Tipe 1 menghasilkan displacement sebesar $2.454 \mathrm{~cm}$ lebih kecil dari batas maksimum deformasi lateral dinding sebesar $8.4 \mathrm{~cm}$ dan momen maksimum sebesar $116.592 \mathrm{kNm}$ lebih kecil dari batas momen maksimum pada tiang sebesar $224.2 \mathrm{kNm}$. Desain Tipe 2 menghasilkan displacement sebesar $2.459 \mathrm{~cm}$ lebih kecil dari batas maksimum deformasi lateral dinding 
sebesar $8.4 \mathrm{~cm}$ dan momen maksimum sebesar $112.861 \mathrm{kNm}$ lebih kecil dari batas momen maksimum pada tiang sebesar $224.2 \mathrm{kNm}$. Desain Tipe 3 menghasilkan displacement sebesar $2.459 \mathrm{~cm}$ lebih kecil dari batas maksimum deformasi lateral dinding sebesar $8.4 \mathrm{~cm}$ dan momen maksimum sebesar $112.859 \mathrm{kNm}$ lebih kecil dari batas momen maksimum pada tiang sebesar $224.2 \mathrm{kNm}$. Dalam analisis ini terdapat hal yang tidak biasa dimana besarnya nilai L2 lebih kecil dari nilai L1 yang pada umumnya nilai L2 sama atau lebih besar dari nilai L1. L1 merupakan panjang tiang bebas dan L2 merupakan panjang tiang menembus permukaan tanah.

2. Model dinding penahan tanah yang digunakan dalam analisis menggunakan program Midas GTS NX ada 3 yaitu Tipe 1 dengan ukuran capping beam $80 \mathrm{~cm}$ x $40 \mathrm{~cm}$ dengan jarak antar tiang $80 \mathrm{~cm}$, Tipe 2 dengan ukuran capping beam $60 \mathrm{~cm}$ x $40 \mathrm{~cm}$ dengan jarak antar tiang $60 \mathrm{~cm}$ dan Tipe 3 dengan ukuran capping beam $60 \mathrm{~cm}$ x $40 \mathrm{~cm}$ dengan jarak antar tiang $40 \mathrm{~cm}$.

3. Desain yang paling cocok digunakan adalah desain Tipe 1 karena membutuhkan biaya yang paling murah sebesar Rp 458.821.479,072 lebih murah dibandingkan desain Tipe 2 dan desain Tipe 3.

\section{Saran}

Berdasarkan proses analisis yang telah dilakukan, ditemukan beberapa masalah dan anomali baru yang belum dapat terpecahkan. Oleh karena itu, peneliti memberi saran untuk penelitian selanjutnya berupa:

1. Analisis dilakukan pada daerah aliran sungai dimana ada pergerakan air atau hidrodinamika sehingga perlu dilakukan perhitungan hidrodinamika agar mendapatkan hasil yang lebih optimal.

2. Dalam menganalisis harga yang digunakan, lebih baik menggunakan daftar harga dan brosur dari produk yang sama agar harga yang didapat lebih efisien.

3. Dinding penahan tanah dianalisis sebagai model 2 dimensi, akan lebih baik apabila dinding penahan tanah dianalisis sebagai model 3 dimensi agar pelat beton untuk menahan tanah dan memastikan beban tanah terbagi rata ke setiap tiang dapat dimodelkan sehingga menghasilkan analisis yang lebih optimal.

4. Data tanah yang diperoleh ada 2 jenis yang berupa data dari boring log dan data dari dutch cone penetration test, akan lebih baik apabila dalam mengkorelasi data tanah yang akan digunakan untuk analisis menggunakan kedua data tersebut agar mendapat hasil yang lebih optimal.

\section{DAFTAR PUSTAKA}

Ameratunga, Jay, Nagaratnam Sivakugan and Braja Das. Correlations of Soil and Rock Properties in Geotechnical Engineering. India: Springer, 2015.

Ankita. 14-485 Capstone Geotechnical Module. $17 \quad$ September $2019 . \quad 10 \quad$ Maret 2020. <https://www.scribd.com/document/426219857/14-485capstonegeotechnicalmodule-pdf >.

Badan Standarisasi Nasional. Persyaratan Perencanaan Geoteknik (SNI 8460:2017). Jakarta: BSN 2017, 2017.

Beton, PT Wijaya Karya. PC Piles. 14 November 2017. 5 May 2020. <https://www.wika-beton.co.id/uploads/2PC-PILES.pdf>.

Bowles, Joseph E. Analisis dan Disain Pondasi, Jilid 1. Jakarta: Erlangga, 1997.

Budhu, Muni. Soil Mechanics and Foundation. United States of America: John Wiley and Sons, 2000.

Dhamdhere, D. R., Dr. V.R. Rathi and Dr. P.K. Kolase. "Design And Analysis Of Retaining Wall." International Journal Of Management, Technology And Engineering (2018).

Gouw, Tjie Liong. Ground Settlement. Jakarta, 2009.

Hamdhan, Indra Noer and Desti Santi Pratiwi. "Analisis Stabilitas Lereng Dalam Penanganan Longsoran di Jalan Tol Cipularang Km. 91+200 dan Km. 92+600 Menggunakan Metode Elemen Hingga (FEM)." (2017).

Leonsius, Calvin. "Analisis Dinding Perkuatan Tanah Dengan Georid Menggunakan Metode Satu Baji (Single Wedge Method) Dan Dua Baji (Two Part Wedge Method)." (2012).

Munawars, Andi. Analisis Beton K-500. $11 \quad$ November $2015 . \quad 15 \quad$ May 2020. $<$ https://www.scribd.com/doc/289345883/Analisis-Beton-K-500>.

Preacast, PT Gemilan Beton. Harga Square Pile. 11 February 2016. 16 May 2020. $<$ http://gemilanbetonprecast.blogspot.com/search?updated-max=2016-02-11T23:52:00-08:00\&maxresults $=7 \& \mathrm{~m}=0>$.

Sabina, Novia. "Proses Analisis Dinding Galian Basement 7 lantai dengan Metode Elemen Hingga." JMTS: Jurnal Mitra Teknik Sipil Vol. 3, No. 1 (2020): 49-58. 